\title{
Hand-assisted or laparoscopic-assisted approach in colorectal surgery: a systematic review and meta-analysis
}

\author{
A. G. J. Aalbers $\cdot$ S. S. A. Y. Biere $\cdot$ \\ M. I. van Berge Henegouwen · W. A. Bemelman
}

Received: 23 July 2007 / Accepted: 7 February 2008/Published online: 24 April 2008

(C) The Author(s) 2008

\begin{abstract}
Background Evidence of benefits of laparoscopic and laparoscopic-assisted colectomies (LAC) over open procedures in gastrointestinal surgery has continued to accumulate. With its wide implementation, technical difficulties and limitations of LAC have become clear. Hand-assisted laparoscopic surgery (HALS) was introduced in an attempt to facilitate the transition from open techniques to minimally invasive procedures. Continuing debate exists about which approach is to be preferred, HALS or LAC. Several studies have compared these two techniques in colorectal surgery, but no single study provided evidence which procedure is superior. Therefore, a systematic review was carried out comparing HALS with LAC colorectal resection.

Methods Eligible studies were identified from electronic databases (Medline, Embase Cochrane) and cross-reference search. The database search, quality assessment, and data extraction were independently performed by two reviewers. Minimal outcome criteria for inclusion were operating time, conversion rate, hospital stay, and morbidity.

Results Out of 468 studies a total of 13 studies were selected for comprehensive review. Two randomized controlled trials (RCT) and 11 non-RCTs, comprising 1017 patients, met the inclusion criteria. Because of possible clinical heterogeneity two groups of procedures were created: segmental colectomies and total (procto)colectomies. In the segmental colectomy group significant differences in favor of the HALS group were seen in operating time (WMD $19 \mathrm{~min}$ ) and conversion rate (OR of 0.3
\end{abstract}

A. G. J. Aalbers · S. S. A. Y. Biere .

M. I. van Berge Henegouwen - W. A. Bemelman ( $₫)$

Department of Surgery, Academic Medical Center, Location G4-

129, Postbox 22660, 1100 DD Amsterdam, The Netherlands

e-mail: w.a.bemelman@amc.uva.nl conversions). In the total (procto)colectomy group a significant difference in favor of the HALS group was seen in operating time (WMD $61 \mathrm{~min}$ ).

Conclusions This systematic review indicates that HALS provides a more efficient segmental colectomy regarding operating time and conversion rate, particularly accounting for diverticulitis. A significant operating time advantage exists for HALS total (procto)colectomy. HALS must therefore be considered a valuable addition to the laparoscopic armamentarium to avoid conversion and speed up complicated colectomies.

Keywords Systematic review - Meta-analysis . Colon · Colorectal · Intestinal surgery - Laparoscopy · Hand-assisted

Throughout the last decade, evidence of the benefits of laparoscopic and laparoscopic-assisted colectomies (LAC) over open procedures in gastrointestinal surgery has continued to accumulate [1]. Faster postoperative recovery, fewer perioperative complications, and shorter duration of hospital stay appear to be the main advantages for patients [1]. With the wide implementation of LAC, the technical difficulties and limitations of the LAC procedures have become clear. The learning curve in laparoscopic procedures is a frequently debated topic when reviewing the limitations of laparoscopy [2-6]. Although the exact number of procedures required to overcome the learning curve is reported with a wide range, it is estimated that at least 50 segmental procedures are necessary to gain sufficient proficiency in LAC. The learning curve is associated with higher morbidity, higher conversion rates, prolonged hospital stay, and increased costs [7]. Reasons for this long learning curve are exposure difficulties of the colon and lack of tactile feedback. 
With the introduction of hand-assisted laparoscopic surgery (HALS) in the early 1990s an attempt was made to facilitate the transition from open techniques to minimally invasive procedures [8]. Loss of pneumoperitoneum and impaired movement of the hand were the main hurdles encountered. These problems were soon resolved with the development of hand-access ports [9]. HALS allows the surgeon to insert his or her hand into the abdominal cavity through a relatively small incision while preserving the ability to work under pneumoperitoneum. This approach allows for hand assistance during laparoscopic surgery and tactile sensation of the lesion that would not be possible with the use of instrumentation alone [10]. Like LAC, HALS is a minimally invasive technique and, along with the advantage of tactile sensation, it seems to eliminate a substantial part of the technical challenges of conventional laparoscopy as well as to provide a more acceptable learning curve for LAC.

There is a continuing debate about which approach is to be preferred, HALS or laparoscopic-assisted or total laparoscopic colectomy. Some consider the HALS bridging technology to have little advantage in terms of overcoming the learning curve, since sound surgical technique is to be preferred over technical appliance [11]. Several studies have compared LAC with HALS in colorectal surgery and no single study has provided evidence for which procedure is superior with respect to morbidity, conversion rate, and hospital stay [12-24]. Therefore, a systematic review was done comparing total laparoscopic and laparoscopic-assisted colorectal resection with hand-assisted colorectal resection for benign or malignant colorectal disease.

\section{Methods}

\section{Literature search}

Two reviewers (AGJA and SSAYB) independently searched the following electronic databases: Medline (1950 to December 2007), Embase (1980 to December 2007), and the Cochrane Library (2007 issue 1). With the assistance of a clinical librarian an extensive search was performed using the search terms: (laparosc* or laparotomy or mini-laparotomy or minimally invasive) and (assisted or device or glove or sleeve or port) and (manual or manually or hand) and (colon or colorectal or colectomy or hemicolectomy or proctocolectomy or proctectomy or sigmoid* or rectal or rectum or recto* or anal or low anterior resection or abdominoperineal resection or hartmann or pfannenst* or resection). The truncation symbol '*' differs in each database and allows retrieval of all suffix variations of a root word.

After identifying relevant titles, the abstracts of these studies were read to decide if the study was eligible. The full article was retrieved when the information in the title and/or abstract appeared to meet the objective of this review. A manual cross-reference search of the bibliographies of relevant articles was conducted to identify studies not found through the computerized search. The "related articles" feature of Pubmed was simultaneously used. All published and unpublished studies comparing laparoscopic or LAC with HALS colorectal resection for benign or malignant colorectal disease were included if they met the study selection criteria. Authors of the eligible studies were requested to send any missing data if needed for further analysis and/or inclusion.

Discordance in study inclusion between the two reviewers was subsequently reviewed and resolved through discussion. There was $100 \%$ agreement on the final interpretation of the data.

\section{Study selection criteria}

Given the paucity of the available evidence addressing the study question, the search was not restricted to randomized controlled trials (RCTs). Controlled clinical trials and comparative studies (including case-matched studies) were included as well. Studies comparing laparoscopic or laparoscopic-assisted colectomy (LAC) with HALS colorectal resection for benign or malignant colorectal disease were eligible for inclusion. There were no language restrictions.

Primary outcome parameters for inclusion were operating time, conversion to open surgery, length of hospital stay, and postoperative (overall) morbidity. The following secondary outcome parameters, when investigated, were also assessed: costs, estimated intraoperative blood loss, incision length, number of trocars used, postoperative pain as measured by analgesic drug or epidural requirement or by analogue scoring scale, (in-hospital) mortality, oncological results (where appropriate), and time to return of gut function as measured by time to first flatus or first bowel movements.

Quality assessment of retrieved articles

Each included article was appraised by two reviewers, who assessed the methodological quality of the selected studies independently. A critical review checklist of the Dutch Cochrane Centre was used to appraise the RCTs [www.cochrane.nl. Last accessed January 2008]. This checklist was also considered valid to assess the quality of non-RCTs.

\section{Data extraction and analysis}

The two reviewers independently extracted data on preformatted sheets. The studies were tabulated and 
methodologically evaluated to assess homogeneity. In the case of heterogeneity between the studies, it would not be justified to pool the assessed outcomes.

\section{Statistical analysis}

Meta-analyses were performed for the four primary outcome parameters: operating time (in minutes), conversion to open surgery (in events per group), length of hospital stay (in days), and postoperative morbidity (in 30 days complications and morbidity, taken together).

Quantative data for the minimal outcome criteria were entered into the software Cochrane Review Manager (RevMan) version 4.3 and analyzed using RevMan Analyses 1.0.5 (Cochrane Collaboration, Oxford, UK). Summary estimates, including 95\% confidence intervals, were calculated. For continuous outcome data (operating time and length of hospital stay) means and standard deviations were used to calculate a weighted mean difference in the meta-analysis. For dichotomous outcomes (conversion to open surgery and postoperative morbidity) the odds ratio (OR) was calculated.

Statistical heterogeneity was tested using $\chi^{2}$ and $I^{2}$ tests. Data were pooled using the random effect model, because moderate heterogeneity was suspected.

\section{Results}

The combined search identified a total of 468 publications. Four hundred and forty studies were rejected based upon abstract evaluation. Of 28 publications, considered potentially relevant, 15 were subsequently excluded (Fig. 1). Thirteen studies published between 2000 and 2007 (except the study of Polle et al., which will be published in 2008) met the inclusion criteria. Two studies were RCTs, the other 11 were non-RCTs. Quality assessment of all the included studies is shown in Table 1.

The 13 studies included in this systematic review involved 1017 patients, of which 499 underwent hand-assisted laparoscopic surgery (HALS) and 518 patients underwent laparoscopic-assisted colectomy (LAC) for colorectal disease. The number of patients included in the 13 studies was relatively small, varying between 13 and 258 patients.

The included studies had several limitations. In none of the included studies were the effect assessors, patients or care providers blinded. Only 5 of the 13 studies described similar postoperative treatment $[12,14,15,19,24]$. Only a few studies described patient baseline characteristics adequately.

Because of possible clinical heterogenicity, two groups of procedures were created in order to be able to perform a meta-analysis of the data for the primary outcome parameters. These two groups were: segmental colectomies and

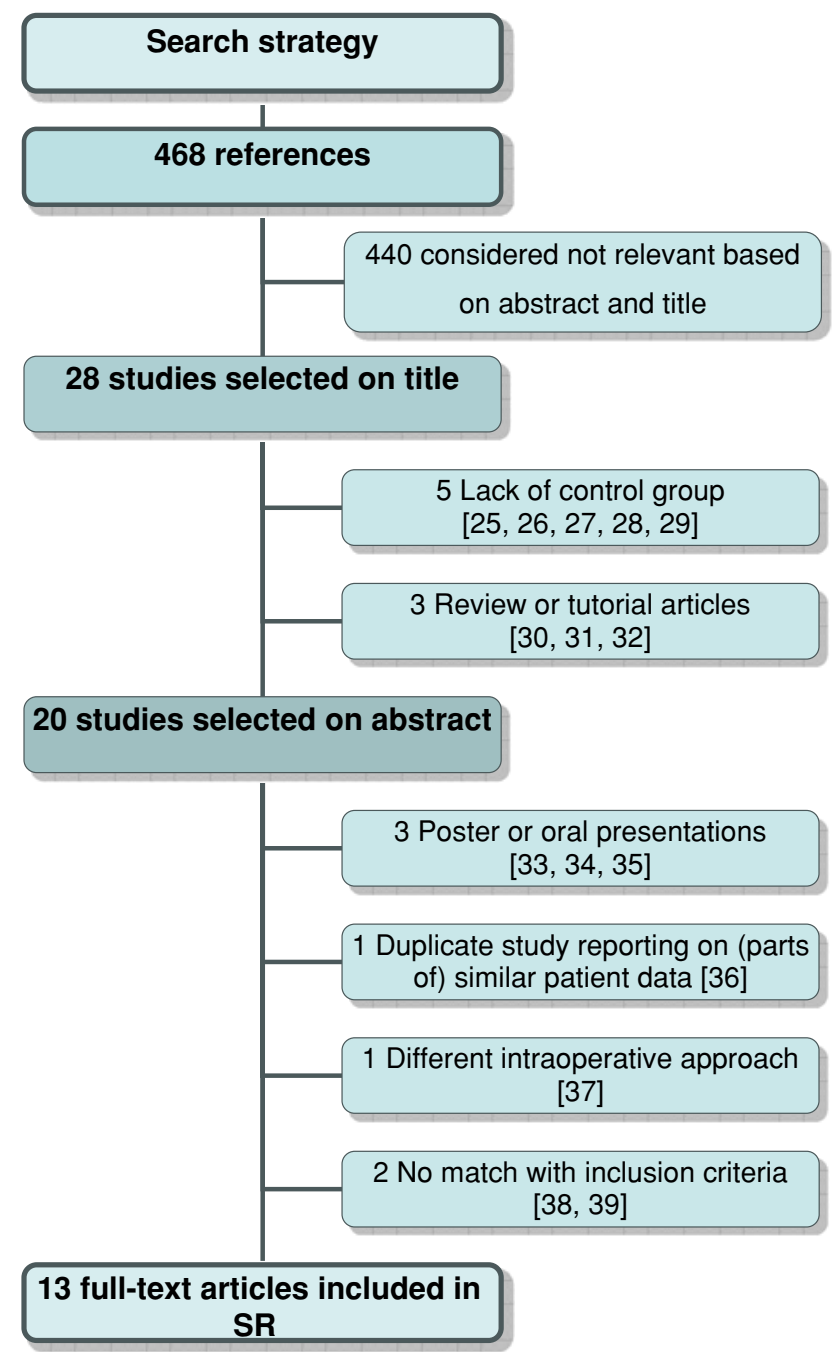

Fig. 1 Search strategy

total (procto)colectomies. The segmental colectomy group consisted of the studies of Targarona et al., Chang et al., Yano et al., Lee et al., and Anderson et al. [14-18] and the proctocolectomy group of Nakajima et al., Rivadeneira et al., and Polle et al. (Table 2) [21, 22, 24]. Because of the inclusion of all possible colorectal procedures we had to exclude the study of the HALS group and the study of Hassan et al. from the meta-analysis [12, 13]. Another reason to exclude the study of Hassan et al. from the metaanalysis was that a greater proportion of HALS patients underwent complex procedures and extensive resections.

Three more studies had to be excluded from the metaanalysis for the following reasons: Ringley et al. because the means and standard deviations of the outcome parameters were not given (not even after request) [19] and the studies of Tjandra et al. and Boushey et al. because bias was introduced in the study [20, 23]: in the study of Tjandra et al. because the HALS approach was generally adopted "in patients who were obese or have had multiple 


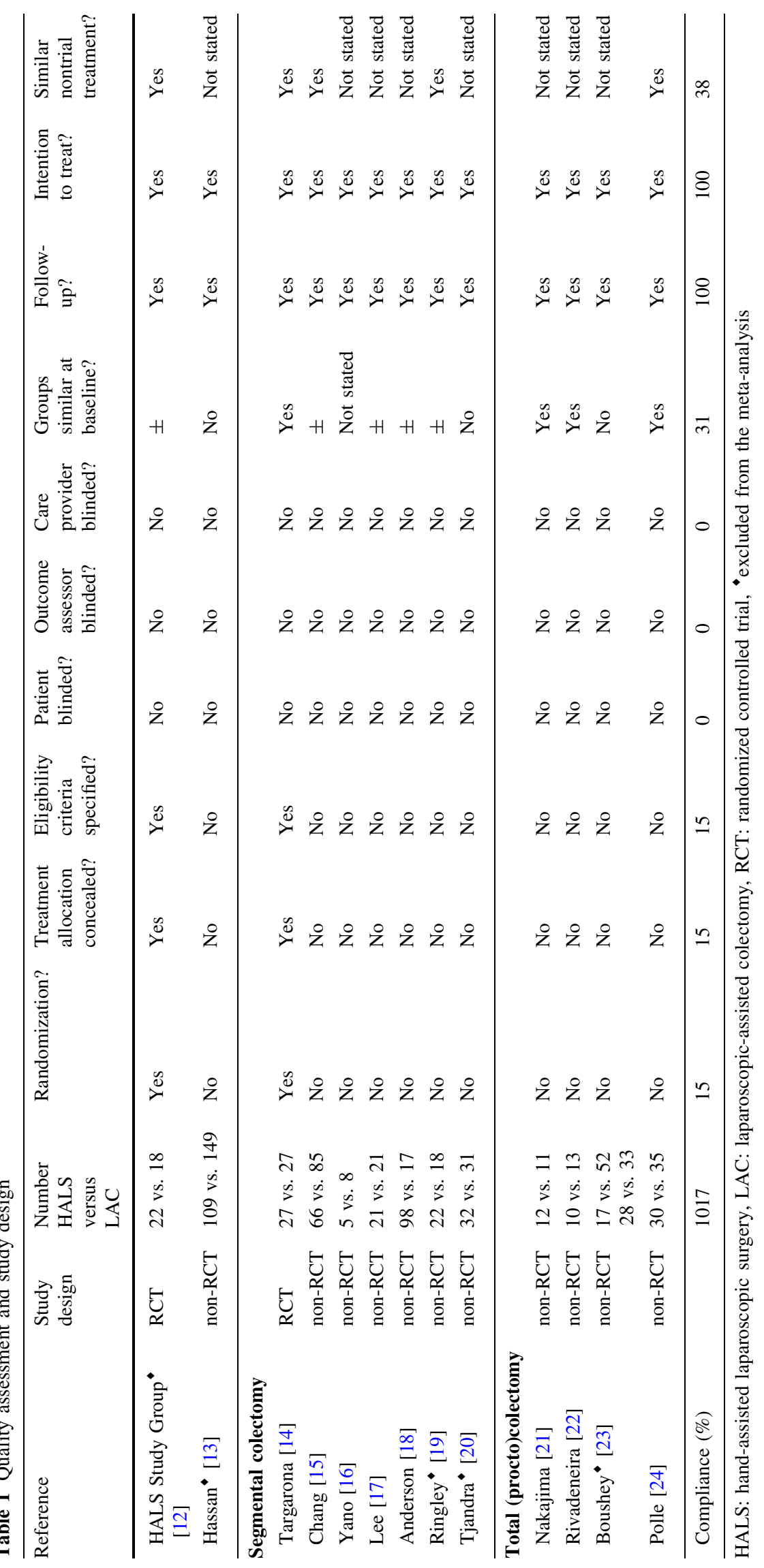




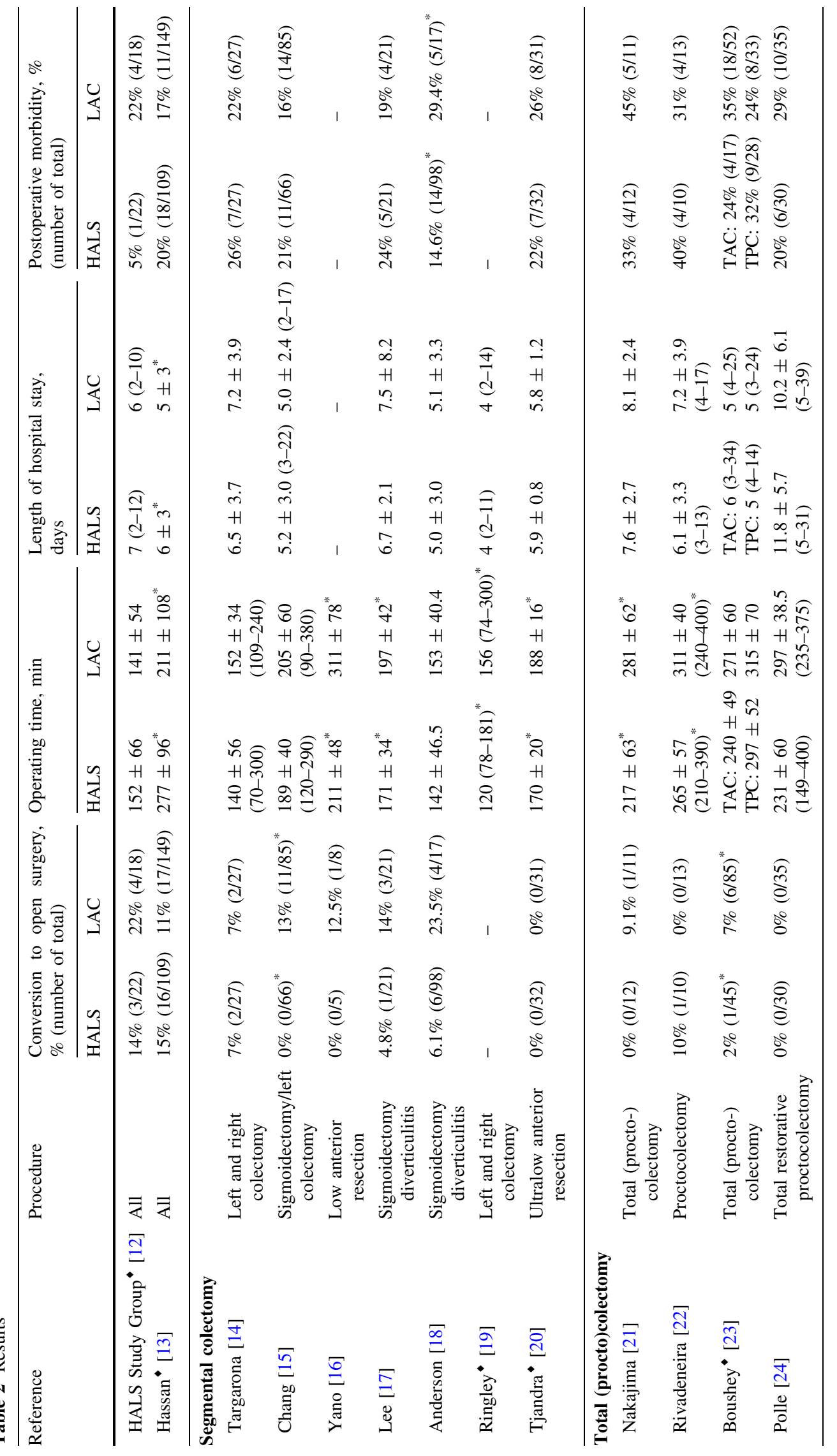




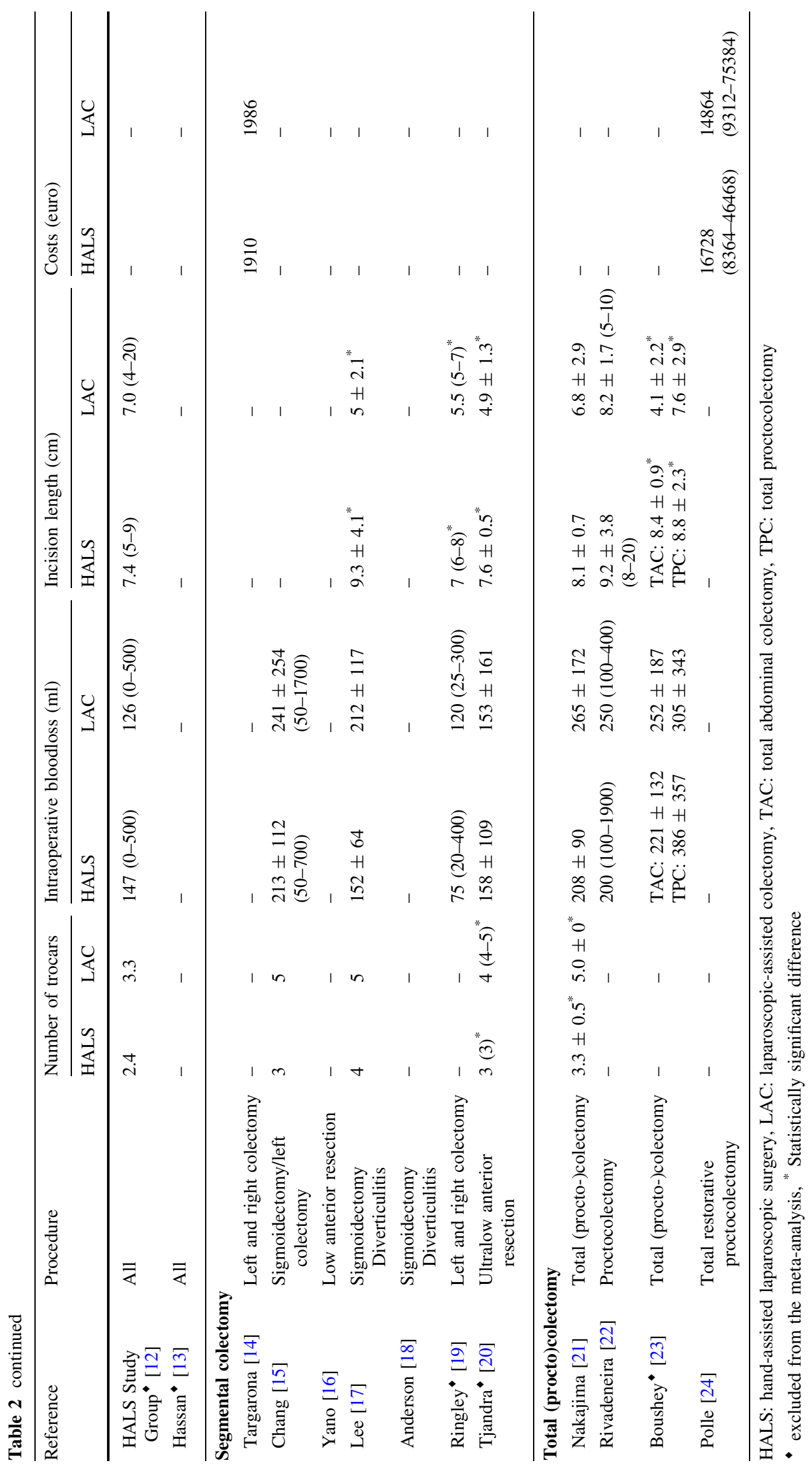


abdominal surgeries" and in the study of Boushey et al. because the HALS technique was recommended "in cases for which straight laparoscopy was not believed to be feasible as a result of obesity or severity of disease".

Primary outcome criteria

\section{Conversion to open surgery}

Two of the 13 studies report a lower conversion rate to open surgery for the HALS group compared to the LAC group. The meta-analysis demonstrated a significant difference only in the segmental colectomy group with an odds ratio of 0.3 conversions in favor of the HALS group (Fig. 2a, b).

\section{Operating time}

Operating times were significantly shorter in the HALS group in 6 of the 13 studies. The differences of the individual studies varied between 18 and 100 min reduction in operating time in the HALS group. Only the study of Hassan et al., which was excluded from the meta-analysis for the reasons mentioned above, found a significantly longer operating time in the HALS group [13]. This remarkable result is probably due to the significantly greater proportion of complex procedures and extensive resections in the HALS group. The meta-analysis demonstrated a significant difference in both the segmental colectomy and the proctocolectomy groups with a weighted mean difference in operating time of 19 and $61 \mathrm{~min}$, respectively, in favor of the HALS procedure (Fig. 3a, b).

\section{Length of hospital stay}

The study of Hassan et al., which was excluded from the meta-analysis for the reasons mentioned above, was the only one to show a significantly longer length of hospital stay in the HALS group [13]. After pooling the data in the meta-analysis no differences were seen (Fig. 4a, b).

\section{Postoperative morbidity}

Due to inconsistency in definitions of complications and morbidity it was impossible to determine which complications would imply morbidity. Therefore, reported overall postoperative morbidity rather than the frequency of predefined complications was abstracted from the articles.

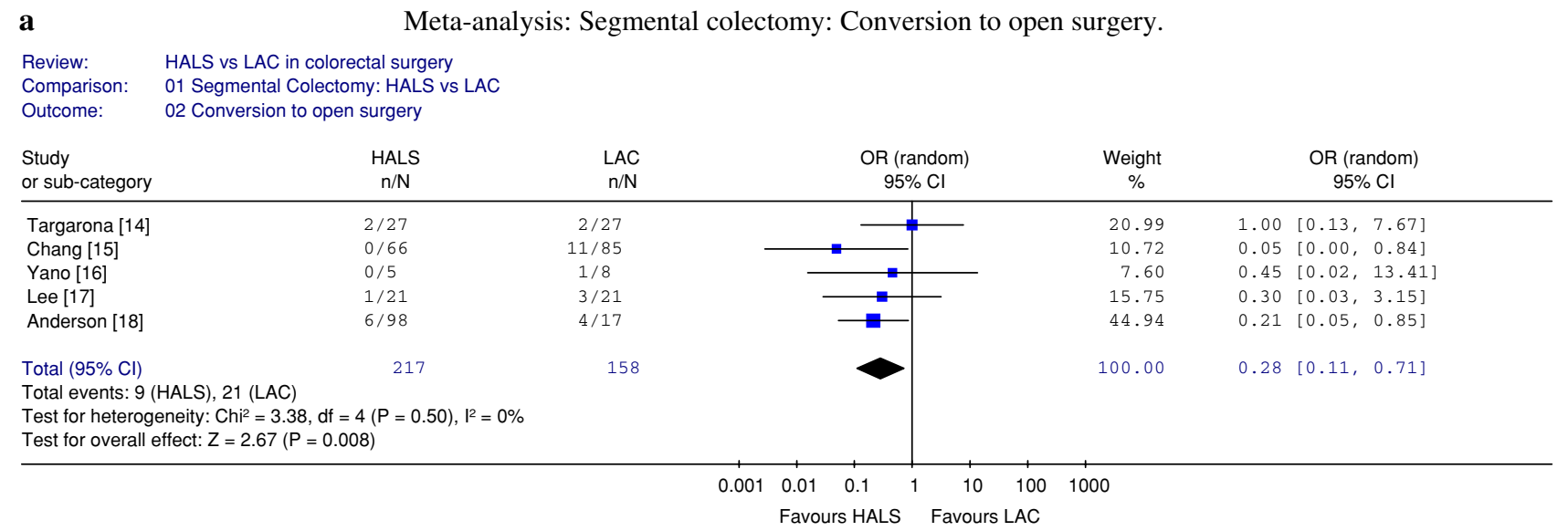

b

Meta-analysis: Total (procto)colectomy: Conversion to open surgery.

Review: HALS vs LAC in colorectal surgery

Comparison: 02 Proctocolectomy: HALS vs LAC

Outcome: $\quad 01$ Conversion to open surgery

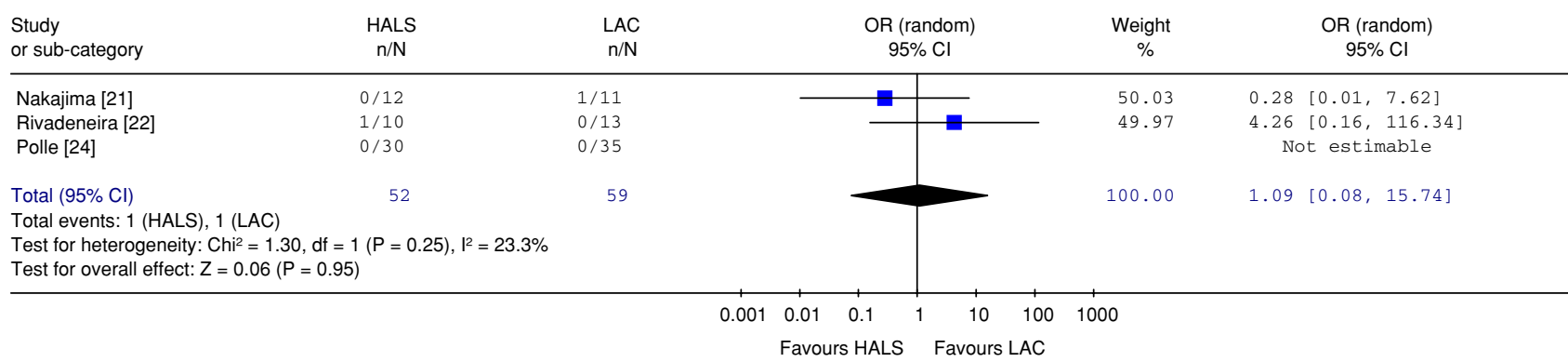

Fig 2 Meta-analysis conversion to open surgery: (a) segmental colectomy and (b) total (procto)colectomy 
a

Review: HALS vs LAC in colorectal surgery

Comparison: 01 Segmental Colectomy: HALS vs LAC

Outcome: $\quad 01$ Operating time

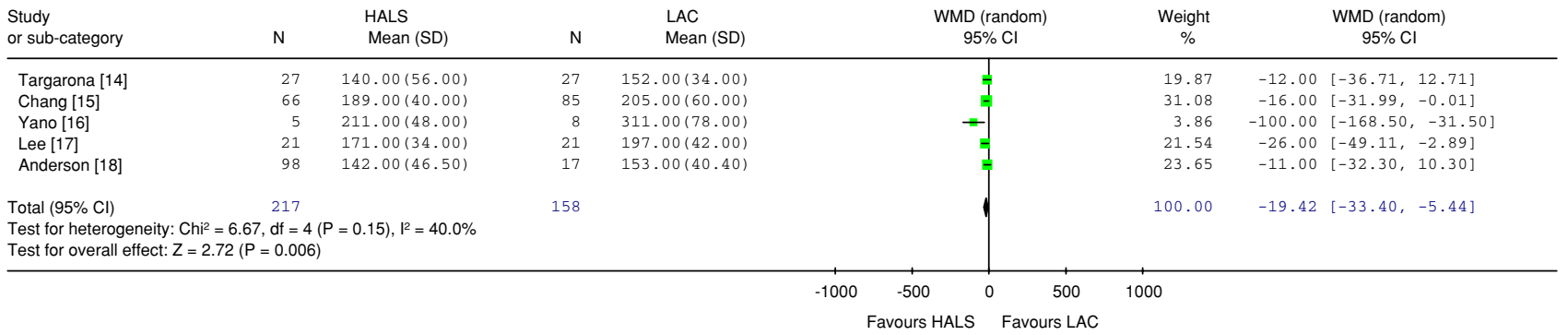

b

Meta-analysis: Total (procto)colectomy: Operating time.

$\begin{array}{ll}\text { Review: } & \text { HALS vs LAC in colorectal surgery } \\ \text { Comparison: } & \text { 02 Proctocolectomy: HALS vs LAC }\end{array}$

Outcome: $\quad 03$ Operating time

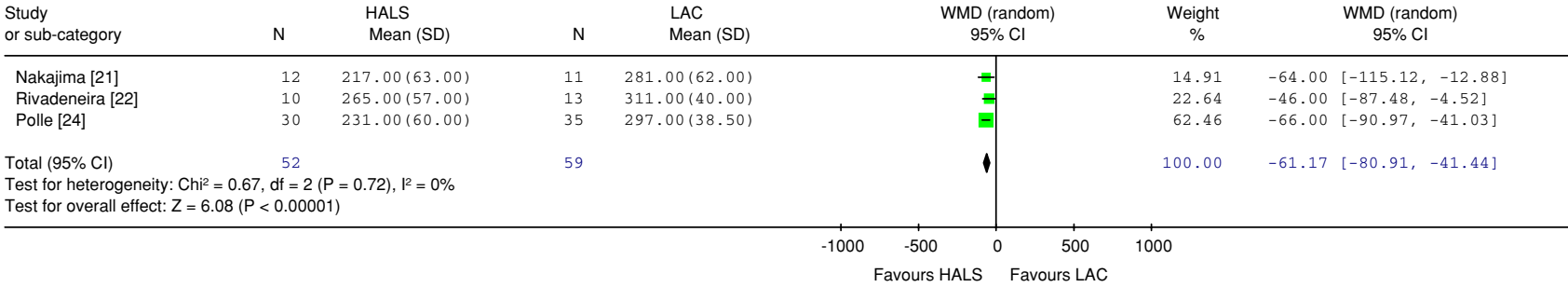

Fig. 3 Meta-analysis operating time: (a) segmental colectomy and (b) total (procto)colectomy

$\mathbf{a}$ Meta-analysis: Segmental colectomy: Length of hospital stay.

Review: HALS vs LAC in colorectal surgery

Comparison: 01 Segmental Colectomy: HALS vs LAC

Outcome: $\quad 03$ Length of hospital stay

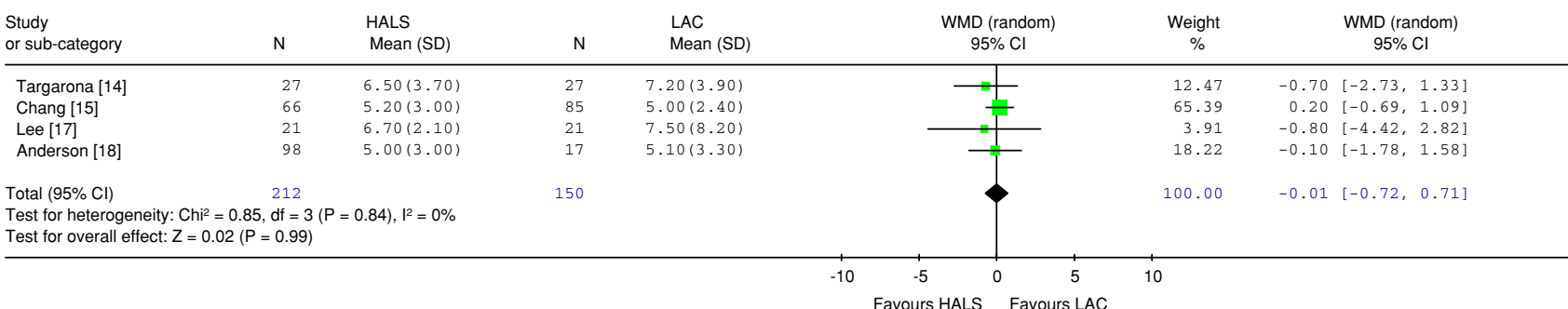

b

Review: HALS vs LAC in colorectal surgery

Comparison: 02 Proctocolectomy: HALS vs LAC

Outcome: 04 Length of hospital stay

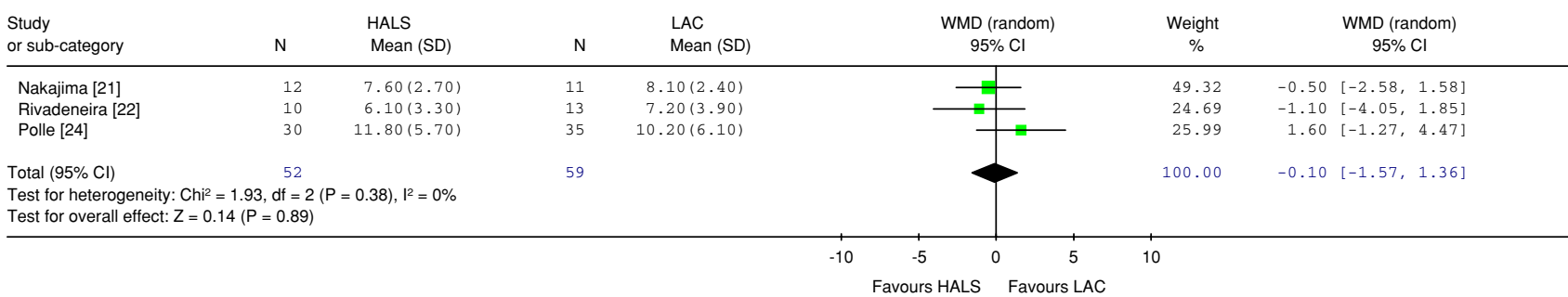

Fig. 4 Meta-analysis length of hospital stay: (a) segmental colectomy and (b) total (procto)colectomy

Anderson et al. reported a significant difference in postoperative morbidity in favor of the HALS group [18]. Postoperative morbidity ranged between $5 \%$ and $40 \%$ in the
HALS group and $16 \%$ and $45 \%$ in the LAC group. This probably reflects differences in the definitions used. The current meta-analysis demonstrated no differences (Fig. 5a, b). 
Review: HALS vs LAC in colorectal surgery

Comparison: 01 Segmental Colectomy: HALS vs LAC

Outcome: $\quad 04$ Postoperative morbidity

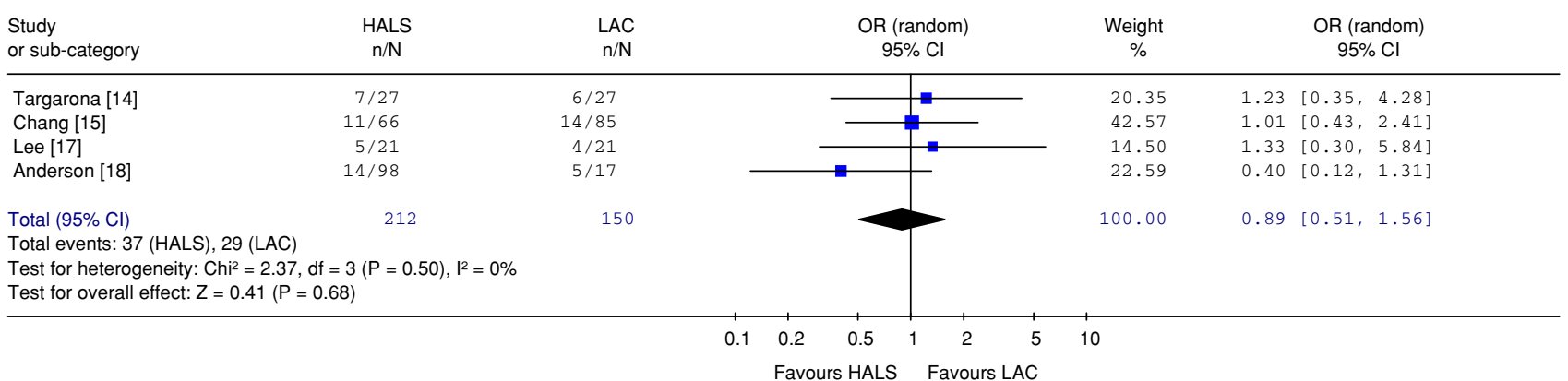

b

$\begin{array}{ll}\text { Review: } & \text { HALS vs LAC in colorectal surgery } \\ \text { Comparison: } & 02 \text { Proctocolectomy: HALS vs LAC }\end{array}$

Outcome: $\quad 02$ Postoperative morbidity

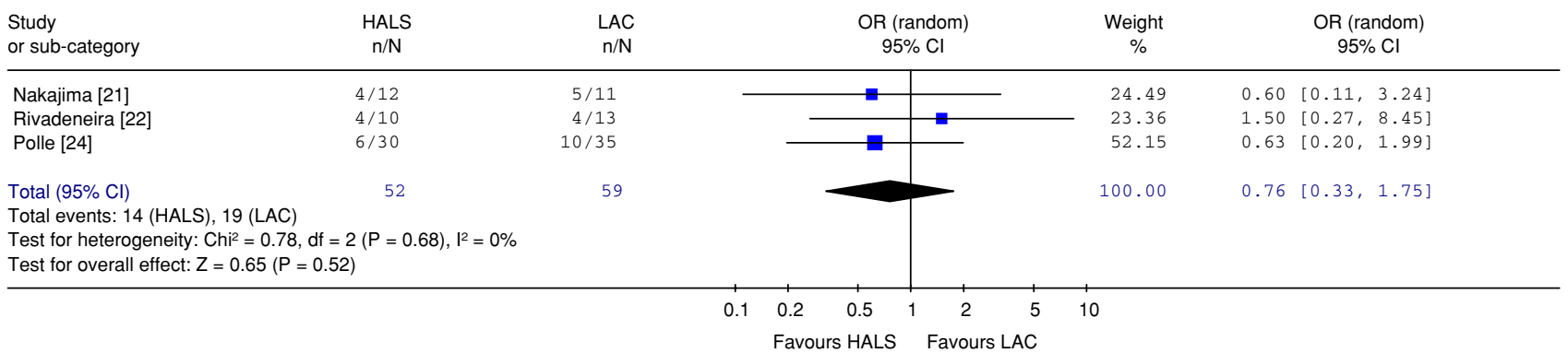

Fig. 5 Meta-analysis postoperative morbidity: (a) segmental colectomy and (b) total (procto)colectomy

Secondary outcome parameters

Because the secondary endpoints were not recorded by all studies and because of missing mean and standard deviation values, the data of the secondary endpoints was not pooled for meta-analysis.

\section{Number of trocars used}

Five of the 13 studies reported on the number of trocars used. Tjandra et al. and Nakajima et al. found a statistically significant difference favoring the HALS group $(p<0.0001)[20,21]$.

\section{Estimated intraoperative blood loss}

Eight of the 13 studies reported on intraoperative blood loss. No significant differences were observed.

\section{Incision length}

Seven of the 13 studies reported on incision length; four of these seven studies reported a significant difference in favor of the LAC group [17, 19, 20, 23]. As could have been expected, incision length was never reported longer for the LAC group.

\section{Costs}

Only two studies, the RCT of Targarona et al. and the nonRCT of Polle et al. reported on costs [14, 24]. Targarona et al. described the total costs for surgery (operating room, salaries of personnel, and materials, disposable and nondisposable), whereas Polle et al. described total costs for surgery as well as overall total costs including surgery and hospital admission. In the study of Polle et al. total costs for surgery were significantly higher in the LAC group $(p<0.001)$, due to the higher costs of disposable material (trocars) and the longer operating time required for LAC surgery. However, overall costs including surgery and hospital admission were $€ 1864$ euros lower in the LAC group compared to the HALS group. This difference, not statistically significant, was explained by the shorter hospital stay in the LAC group. Targarona's studies did not find a significant difference in total costs for surgery between the LAC and HALS group. 


\section{Postoperative pain}

None of the four reporting studies demonstrated a difference in postoperative pain.

\section{In-hospital mortality}

Only one patient out of a total of 1017 patients died in hospital. This patient was a 77-year-old man with metastatic colon cancer who died on the fourth postoperative day from respiratory failure after having been operated in the LAC group, as described by Chang et al. [15]. An overall mortality rate of $0.1 \%$ demonstrates that both LAC and HALS procedures are safe procedures if performed by dedicated surgeons.

\section{Oncological results}

Only Targarona et al. investigated the oncological features of the different procedures [14]. They performed an analysis of the risk of tumor dissemination by doing a cytological analysis of peritoneal lavage fluid obtained at the beginning and the end of the procedure and by evaluating the quality of the resected specimen. They found no differences between the two groups.

\section{Time to return of gut function}

Almost all included studies reported on the time to return of gut function. In the segmental colectomy group Tjandra et al. reported a significant shorter time to return of gut function in favor of the LAC group ( $p<0.0001$ ) [20]. Two studies in the total (procto)colectomy group reported a significant difference: Rivadeneira et al. reported a shorter time to return of gut function in favor of the HALS group (1.6 \pm 0.7 vs. $3.1 \pm 2.1$ days; $p=0.02$ ) [22], whereas Polle et al. demonstrated the contrary, i.e., a shorter time in favor of the LAC group (5 vs. 6 days; $p=0.004$ ) [24]. No data were available with respect to protocolised perioperative treatment.

\section{Discussion}

This systematic review and meta-analysis comparing handassisted versus laparoscopic-assisted or total laparoscopic colectomies demonstrated that there is an advantage for hand-assisted colectomy with respect to operating time and conversion rate, while morbidity and hospital stay were not significantly different.

Hand-assisted segmental colectomy particularly benefited from a significant lower conversion rate and handassisted total (procto)colectomy benefited from a significant $(1 \mathrm{~h})$ shorter operating time.
Considering the segmental colectomies it has to be noted that two of the seven included studies exclusively included patients with diverticulitis [17, 18], while the study by Chang et al. [15] included approximately $70 \%$ of patients with diverticulitis. In the study of Targarona most patients underwent surgery because of cancer [14], Ringley et al. described patients with colonic cancer [19] while Yano et al. and Tjandra et al. described patients with rectal cancer $[16,20]$. HALS is probably particularly suitable for the surgical treatment of diverticulitis, where the presence of an inflammatory mass might preclude a successful laparoscopic-assisted approach. Using the handport it is probably easier to handle the diverticular phlegmon and remove it from the pelvis using finger fraction. Operation time and conversion rates might benefit from this.

In the case of colorectal malignancy, fixed masses are not commonly treated laparoscopically, obviating the need for a handport to avoid conversion. It is therefore not surprising that Targarona did not find any differences in his randomized controlled trial [14].

In total laparoscopic or laparoscopic-assisted colorectal surgery for cancer the medial-to-lateral approach is theoretically of benefit, because the vascular supply of the affected bowel is ligated early in the operation avoiding possible hematogeneous tumor spill. A medial-to-lateral approach is more difficult in HALS because applying the medial approach the hand can only lift the colon and cannot provide adequate traction and countertraction to create the submesenteric tunnel at the level of the major blood vessels. A possible solution is retraction of the bowel by the assistant, enabling the surgeon to use two instruments for dissection.

Targarona et al. concluded that the HALS technique may be "a useful adjunct to difficult situations during laparoscopic surgery" [14]. Lee et al. made a subdivision into uncomplicated and complicated diverticulitis [17]. Especially in the complicated cases an even more pronounced benefit in favor of the HALS group was demonstrated. Operating time (more than $1 \mathrm{~h}$ shorter) and conversion rate (10\% vs. $75 \%$ ) were lower in these complicated cases in the HALS group compared to the LAC group.

The study by Ringley et al. demonstrated significantly more lymph nodes harvested after colorectal resection in the HALS group, compared with the LAC group [19]. Followup was very short and therefore it remains to be seen whether this finding is of clinical relevance. Tjandra et al. found no difference between the two groups in the number of lymph nodes harvested after rectal resection [20].

The most important advantage of HALS in total (procto)colectomy was an important reduction in operating time, making the operation more efficient. One must bear in mind, however, that the studies comparing HALS with total laparoscopic proctocolectomy actually compared a 
HALS combined with an open proctectomy and pouch creation via the Pfannenstiel with a total laparoscopic restorative proctocolectomy including laparoscopic rectum extirpation [21, 22, 24]. Boushey et al. described that "some or all of the rectal mobilization was performed laparoscopically and then a Pfannenstiel incision is formed, through which proctectomy could be completed in an open fashion when necessary" in the LAC group [23].

The aspect of costs of both procedures could only be partially addressed because only two of the included studies reported on this subject $[14,24]$. The costs of the hand device increases costs for HALS, but shorter operating time, fewer conversions, and the reduced number of trocars used could counterbalance this in favor of HALS.

Only two RCTs were available for inclusion in this systematic review. Patient baseline characteristics were adequately described in only a few studies, but overall the quality of the included studies was acceptable. Because of the small number of patients included in the reviewed studies, pooling of data was essential to draw more robust conclusions. Clinical heterogeneity had to be ruled out by dividing the included studies into two different surgical groups, i.e., segmental colectomy and total (procto)colectomy. When the meta-analysis was performed, a random effects model was used to rule out possible statistical heterogenicity. With more than acceptable $\chi^{2}$ and $I^{2}$ values significant weighted mean differences were demonstrated for operating time (in both groups) and conversion rate (in the segmental colectomy group).

Criticasters of hand-assisted laparoscopic surgery have argued that this kind of surgery, using a handport, is not laparoscopic surgery in the strict sense. The authors agree with J. Rosser who elegantly verbalized a comment on the review of Targarona, where he stated that handports should not be used to overcome the learning curve obviating the need for proper education and proficiency in laparoscopic surgery [11]. It has its place in avoiding conversion and in making time-consuming operations more efficient by reducing operating time.

In conclusion, this systematic review indicates that HALS provides a more efficient segmental colectomy regarding operating time and conversion rate, particularly in colectomies for diverticulitis. A significant operating time advantage exists for HALS total (procto)colectomy. HALS must therefore be considered a valuable addition of the laparoscopic armamentarium to avoid conversion and speed up complicated colectomies.

Open Access This article is distributed under the terms of the Creative Commons Attribution Noncommercial License which permits any noncommercial use, distribution, and reproduction in any medium, provided the original author(s) and source are credited.

\section{References}

1. Schwenk W, Haase O, Neudecker J, Muller JM (2005) Short term benefits for laparoscopic colorectal resection. Cochrane Database Syst Rev 20(3):CD003145

2. Dincler S, Koller MT, Steurer J, Bachmann LM, Christen D, Buchmann P (2003) Multidimensional analysis of learning curves in laparoscopic sigmoid resection: eight-year results. Dis Colon Rectum 46:1371-1378

3. Bemelman WA, Gouma DJ (2005) Laparoscopic-assisted resection of colorectal tumours. Ned Tijdschr Geneeskd 149:21482152

4. Schlachta CM, Mamazza J, Seshadri PA, Cadeddu M, Gregoire R, Poulin EC (2001) Defining a learning curve for laparoscopic colorectal resections. Dis Colon Rectum 44:217-222

5. Agachan F, Joo JS, Sher M, Weiss EG, Nogueras JJ, Wexner SD (1997) Laparoscopic colorectal surgery. Do we get faster?. Surg Endose 11:331-335

6. Bennett CL, Stryker SJ, Ferreira MR, Adams J, Beart RW Jr (1997) The learning curve for laparoscopic colorectal surgery. Preliminary results from a prospective analysis of 1194 laparoscopic-assisted colectomies. Arch Surg 132:41-44

7. Tekkis PP, Senagore AJ, Delaney CP, Fazio VW (2005) Evaluation of the learning curve in laparoscopic colorectal surgery: comparison of right-sided and left-sided resections. Ann Surg 242:83-91

8. Ballantyne GH, Leahy PF (2004) Hand-assisted laparoscopic colectomy: evolution to a clinically useful technique. Dis Colon Rectum 47:753-765

9. Darzi A (2000) Hand-assisted laparoscopic colorectal surgery. Surg Endosc 14:999-1004

10. Naitoh T, Gagner M, Garcia-Ruiz A, Heniford BT, Ise H, Matsuno S (1999) Hand-assisted laparoscopic digestive surgery provides safety and tactile sensation for malignancy or obesity. Surg Endosc 13:157-160

11. Targarona EM, Gracia E, Rodriguez M, Cerdan G, Balague C, Garriga J, Trias M (2003) Hand-assisted laparoscopic surgery. Arch Surg 138:133-141

12. HALS Study Group (2000) Hand-assisted laparoscopic surgery vs. standard laparoscopic surgery for colorectal disease: a prospective randomized trial. Surg Endosc 14:896-901

13. Hassan I, Nancy You Y, Cima RR, Larson DW, Dozois EJ, Barnes SA, Pemberton JH (2007) Hand-assisted versus laparoscopic-assisted colorectal surgery: practice patterns and clinical outcomes in a minimally-invasive colorectal practice. Surg Endosc Aug [Epub ahead of print]

14. Targarona EM, Gracia E, Garriga J, Martinez-Bru C, Cortes M, Boluda R, Lerma L, Trias M (2002) Prospective randomized trial comparing conventional laparoscopic colectomy with handassisted laparoscopic colectomy: applicability, immediate clinical outcome, inflammatory response, and cost. Surg Endosc 16:234239

15. Chang YJ, Marcello PW, Rusin LC, Roberts PL, Schoetz DJ (2005) Hand-assisted laparoscopic sigmoid colectomy: helping hand or hindrance? Surg Endosc 19:656-661

16. Yano H, Ohnishi T, Kanoh T, Monden T (2005) Hand-assisted laparoscopic low anterior resection for rectal carcinoma. J Laparoendosc Adv Surg Tech A 15:611-614

17. Lee SW, Yoo J, Dujovny N, Sonoda T, Milsom JW (2006) Laparoscopic vs. hand-assisted laparoscopic sigmoidectomy for diverticulitis. Dis Colon Rectum 49:464-469

18. Anderson J, Luchtefeld M, Dujovny N, Hoedema R, Kim D, Butcher J (2007) A comparison of laparoscopic, hand-assist and open sigmoid resection in the treatment of diverticular disease. Am J Surg 193:400-403 
19. Ringley C, Lee YK, Iqbal A, Bocharev V, Sasson A, McBride CL, Thompson JS, Vitamvas ML, Oleynikov D (2007) Comparison of conventional laparoscopic and hand-assisted oncologic segmental colonic resection. Surg Endosc 24: Epub ahead of print

20. Tjandra JJ, Chan MKY, Yeh CH (2007) Laparoscopic- vs. handassisted ultralow anterior resection: a prospective study. Dis Colon Rectum Dec [Epub ahead of print]

21. Nakajima K, Lee SW, Cocilovo C, Foglia C, Sonoda T, Milsom JW (2004) Laparoscopic total colectomy: hand-assisted vs. standard technique. Surg Endosc 18:582-586

22. Rivadeneira DE, Marcello PW, Roberts PL, Rusin LC, Murray JJ, Coller JA, Schoetz DJ Jr (2004) Benefits of hand-assisted laparoscopic restorative proctocolectomy: a comparative study. Dis Colon Rectum 47:1371-1376

23. Boushey RP, Marcello PW, Martel G, Rusin LC, Roberts PL, Schoetz DJ Jr (2007) Laparoscopic total colectomy: an evolutionary experience. Dis Colon Rectum 50: 1512-1519

24. Polle SW, van Berge Henegouwen MI, Slors FM, Cuesta MA, Gouma DJ, Bemelman WA (2008) Total laparoscopic restorative proctocolectomy: are there any advantages compared with the open and hand-assisted approach? Dis Colon Rectum [Epub ahead of print]

25. Southern Surgeons' Club Study Group (1999) Handoscopic surgery: a prospective multicenter trial of a minimally invasive technique for complex abdominal surgery. Arch Surg 134:477-485

26. Araki Y, Noake T, Kanazawa M, Yamada K, Momosaki K, Nozoe Y, Inoue A, Ishibashi N, Ogata Y, Shirouzu K (2004) Clipless hand-assisted laparoscopic total colectomy using Ligasure Atlas. Kurume Med J 51:105-108

27. Dostalik J, Martinek L, Vavra P, Andel P, Satinsky L, Richter V, Mazur M, Foltys A (2002) Hand-assisted laparoscopic surgery of the colorectum. Rozhl Chir 81:560-563

28. Wellmann K, Deling O, Kolvenbach R (1997) The Pfannenstiel incision-An alternative access for open and laparoscopicassisted resection of colon and rectum. Aktuelle Chirurgie 32
29. Gorey TF, O’riordain MG, Tierney S, Buckley D, Fitzpatrick JM (1996) Laparoscopic-assisted rectopexy using a novel handaccess port. J Laparoendosc Surg 6:325-328

30. Kostewicz W (2005) Hand-assisted laparoscopic sigmoidectomy GelPort - Technical remarks: Commentary. Polski Przeglad Chirurgiczny 77

31. Kusminsky RE, Boland JP, Tiley EH et al (1996) Hand-assisted laparoscopic surgery[comment]. Dis Colon Rectum 39:111

32. Smoczkiewicz M (2005) Hand-assisted laparoscopic sigmoidectomy GelPort - Technical remarks. Polski Przeglad Chirurgiczny 77

33. Bergamini A, Borrelli A, Reddavide S (2003) Hand-assisted laparoscopic surgery for colorectal cancer [ABSTRACT]. Surg Endosc 17:s218-s314

34. Burgel JS, Navarro F, Michel J (1997) Prospective randomised study: laparoscopy vs. dexterity-glove for left colectomy for benign disease [ABSTRACT]. Surg Endosc 11:534

35. Naar D, Alkoraishi A, Begos DG (2001) Comparison of laparoscopic hand-assisted versus total laparoscopic colectomy [ABSTRACT]. J Soc Laparoendosc Surg 5:319-406

36. Braveman JM, Marcello PW, Rusin LC et al (2003) Handassisted laparoscopic resection for diverticulitis: a comparison with laparoscopic resection [ABSTRACT]. Surg Endosc 17:S218-S314

37. Miura Y, Mitsuta H, Yoshihara T, Ohshiro Y, Okajima M, Asahara T, Dohi K (2001) Gasless hand-assisted laparoscopic surgery for colorectal cancer: an option for poor cardiopulmonary reserve. Dis Colon Rectum 44:896-898

38. Reichenbach DJ, Tackett AD, Harris J, Camacho D, Graviss EA, Dewan B, Vavra A, Stiles A, Fisher WE, Brunicardi FC, Sweeney JF (2006) Laparoscopic colon resection early in the learning curve: what is the appropriate setting? Ann Surg 243:730-735

39. Sjoerdsma W, Meijer DW, Jansen A, den Boer KT, Grimbergen CA (2000) Comparison of efficiencies of three techniques for colon surgery. J Laparoendosc Adv Surg Tech A 10:47-53 